\title{
The Effect of General Low Frequency Vibration on EnergyBalance of a Human Being
}

\author{
Z. DAMIJAN ${ }^{a, *}$ AND A. UHRYŃSKI ${ }^{b}$ \\ AGH - University of Science and Technology, Faculty of Mechanical Engineering and Robotics \\ ${ }^{a}$ Department of Mechanics and Vibroacoustics \\ ${ }^{b}$ Department of Machine Design and Technology \\ al. A. Mickiewicza 30, 30-059 Krakow, Poland
}

\begin{abstract}
The work presents the research and analysis concerning general low frequency vibration and its effect on energy balance of a human organism (a comparison with a control group). The research was conducted in two phases: a group exposed to vibration and a control group. An exposed group (28 participants) took part in 19 training sessions, each lasting $20 \mathrm{~min}$, of low frequency vibration (around $3.2 \mathrm{~Hz}$ in standing position) applied to each participant at fixed time of the day. Before and after the session, the thermographic images were taken and deep temperature was taken too. The control group (33 participants) also took part in 19 everyday 20-min sessions with no vibrations and only measurements conducted. The results were analysed concerning statistics using Statistica. For the sake of the analysis the significance level was $p=0.05$, the parametric $\mathrm{T}-$ test, and the non-parametric Kołmogorow-Smirnow tests were used for two groups of independent variables. Having conducted the research and analysis, one can state that 20-min exposure to low frequency vibration results in significant positive changes in chosen parameters.
\end{abstract}

DOI: 10.12693/APhysPolA.123.970

PACS: 87.50.yt, 07.20.-n

\section{Introduction}

The vibration training is a new popular form of sport, fitness keeping or rehabilitation [1] which resulted in the growth of new vibration platforms.

Many researchers write about the stimulating vibration influence on a circulatory system: blood vessels widen, the blood circulation increases, muscles are better provided with oxygen and other nutrients [2-4]. Vibration can improve saturation of haemoglobin by oxygen and the use of oxygen by tissues. That can result from, among other things: widening of blood vessels, blood circulation improvement (especially concerning microcirculation), improvement of hydro-dynamic feature of blood (which leads to smaller risk of clots) [5]. Vibration has a significant influence on circulation system work and thanks to that it can decrease the negative effects of sitting position [6]. Kerschan-Schindl et al. [7] think that low frequency vibration of the whole body (all the muscles) does not have negative effect on circumferential blood circulation, contrary to high frequency vibration.

The above-mentioned reports demand new research to establish the best parameters of stimulus and vibration range, in order to obtain the best effects of such training upon human organism.

\section{Methodology of research}

Two experimental stands were constructed in the AGH Laboratory in Kraków, enabling to induce general vertical vibration with acceleration of $1.74 \mathrm{~m} / \mathrm{s}^{2}$, amplitude

\footnotetext{
*corresponding author; e-mail: damijan@imir.agh.edu.pl
}

$4 \mathrm{~mm}$, and vibration frequency about $3.2 \mathrm{~Hz}$. Persons examined during the training on the vibration platforms are shown in Fig. 1.

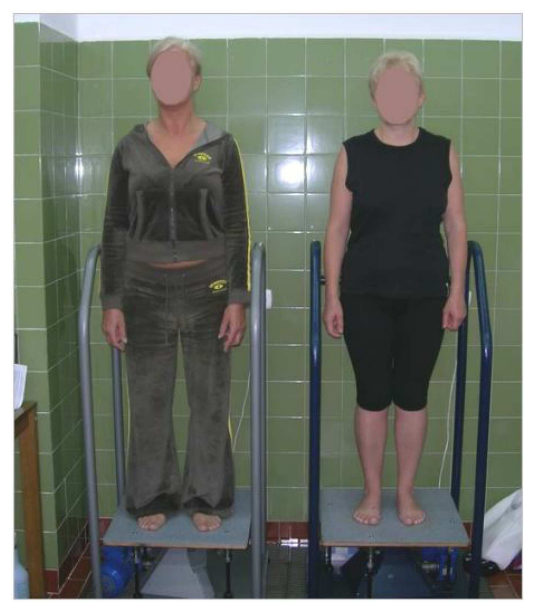

Fig. 1. Persons examined during the training on the platforms.

The participants of the experiment were chosen randomly from the sanatorium patients or volunteered on the arrival day. No special disease was preferred. All the participants suffered from a motion organ complaint which was why they came to the sanatorium. The experiment was conducted in July and November in KrynicaZdrój where 28 participants were chosen (an exposure group) and 33 (a control group). The participants were informed about the experiment and volunteered to take part. Table I presents characteristics of the examined groups. 
TABLE I

Characteristics of the examined groups.

\begin{tabular}{c|c|c|c|c|c}
\hline \hline \multirow{2}{*}{$\mathrm{c}$} & \multicolumn{2}{|c|}{ range } & average & median & SD $^{* *}$ \\
\cline { 2 - 5 } & min & max & & & \\
\hline \multicolumn{6}{c}{ KRYNICA - July } \\
\hline Age [y] & 42 & 61 & 52.76 & 54.00 & 5.16 \\
Height [m] & 1.53 & 1.78 & 1.63 & 1.62 & 0.07 \\
Mass [kg] & 49.00 & 92.00 & 67.55 & 65.70 & 11.10 \\
BMI* & 20.13 & 36.39 & 25.62 & 24.8 & 3.57 \\
\hline \multicolumn{6}{c}{ KRYNICA - November } \\
\hline Age [y] & 32 & 61 & 52.70 & 54.00 & 6.60 \\
\hline Height [m] & 1.50 & 1.78 & 1.62 & 1.63 & 0.05 \\
Mass [kg] & 51.00 & 96.00 & 67.00 & 65.06 & 10.06 \\
BMI* & 18.82 & 44.29 & 26.10 & 25.64 & 5.11 \\
* BMI — body mass index, ** SD - standard deviation
\end{tabular}

The research concerning the effect of low frequency vibration on energy balance of a human being included the measurement of deep temperature and the thermographic images of the examined person's legs before and after the exposure to vibration (a control group without a stimulus). The results obtained underwent the numerical and statistic analysis. A participant during taking images of her legs is shown in Fig. 2.
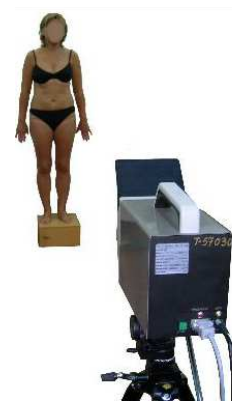
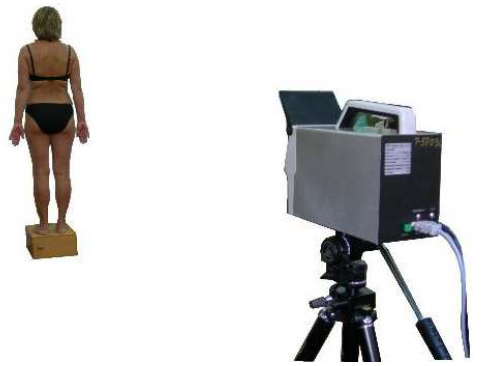

Fig. 2. Participants during thermographic examination.

The usage of thermographic images is more and more popular; also is used in new fields. In some areas, the thermographic research has become common and even necessary [8-11].

In many conditions the system of keeping thermal equilibrium may not work properly, thus every general or local increase or decrease of temperature contains a diagnosis information. When the body temperature is far from normal we may call it a condition. However, a local increase or decrease of temperature is connected with a growth or fall of metabolism [12].

Everybody whose temperature is higher than an absolute zero is a source of infrared radiation and its intensity depends on temperature and characteristics of the organism. Creating the image means the registration of the emitted radiation by a camera and then transforming it into a color temperature map. That is why a thermo- graphic system is a kind of thermometer which allows to measure the temperature in many distant places at the same time.

The researchers used the thermographic VIGO camera type $\mathrm{v}-20$. A thermographic camera is a measuring device used for remote non-contact temperature measurement and the thermographic images help analyse its distribution on the examined object. The example of thermograph of legs is shown in Fig. 3. To measure the body temperature, an electronic Gentle Temp 510 thermograph was used. The temperature was measured in the aural canal. The Gentle Temp 510 thermometer is used for quick measurement of temperature in ears. The device is safe, quick, and accurate. The measurement takes place in the aural canal next to eardrum. The thermometer detects the infrared heat emitted by the eardrum and surrounding cells. Clinic studies show that ear is an ideal place for measurement of body temperature. Eardrum has the same blood vessels as brain. Thus ear is an accurate indicator of the inner (deep) body temperature.

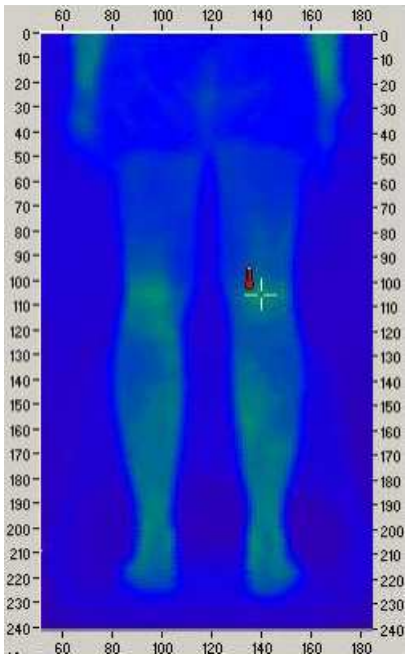

Fig. 3. Example of a thermograph.

The computer program THERM V-20, linked to the camera, was used to analyse temperatures. It offers great possibilities of processing the thermographic images including the analysis of chosen parts only or reading the temperature in every point of a thermograph.

The analysis of particular data groups obtained in the experiment was started with the hypothesis which was later verified according to an established scheme of statistic concluding. After formulating the hypothesis, a test of significance was chosen. The algorithm describing a choice of applied test in particular cases is presented in Fig. 4. Two following phases of analysis; calculating the value of checking test based on the test results and finding a critical value from the tables with a test of significance established (for biomedical research at $p=0.05$ level), were conducted using the STATISTICA 8.1. computer program. 


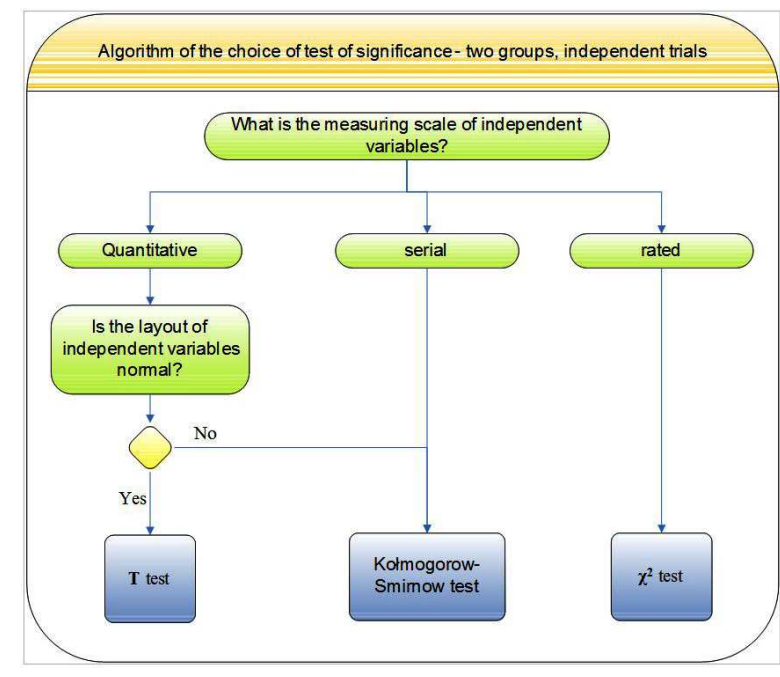

Fig. 4. Algorithm of the choice of test.

For the quantitative analysis, the maximum, the minimum, and the average temperatures were chosen from the leg area for the images taken from the front $T_{\max }$ front and back $T_{\max }$ back of the patient together with deep temperature measured in the ear canal $T$. The percentage increase of these variables in both groups ( $E$ and $K$ ) obtained before and after the exposure to vibration (a control group with no stimulus) was compared (Figs. 5 and 6). Detailed descriptive statistics is presented in Table II.

TABLE II

Descriptive statistics.

\begin{tabular}{c|c|c|c|c|c|c}
\hline \hline$T[\%]$ & $\mathrm{p}$ & $\mathrm{av}$ & $\mathrm{min}$ & $\max$ & $\mathrm{SD}$ & $\mathrm{SE}$ \\
\hline$T_{\max \text { front }} E$ & & -0.578 & -3.070 & 1.025 & 1.064 & 0.198 \\
$T_{\max \text { front }} K$ & $<\mathbf{0 . 0 0 6}$ & 0.260 & -1.602 & 3.463 & 1.180 & 0.205 \\
$T_{\min \text { front }} E$ & & 0.972 & -0.781 & 2.512 & 0.980 & 0.182 \\
$T_{\min \text { front }} K$ & $>0.851$ & 0.890 & -3.720 & 6.275 & 2.134 & 0.377 \\
$T_{\text {av front }} E$ & & -0.035 & -2.571 & 1.195 & 0.968 & 0.180 \\
$T_{\text {av front }} K$ & $>0.363$ & 0.264 & -2.054 & 3.775 & 1.494 & 0.264 \\
$T_{\max \text { back }} E$ & & -0.523 & -2.647 & 1.979 & 1.072 & 0.199 \\
$T_{\max \text { back }} K$ & $<\mathbf{0 . 0 1 2}$ & 0.187 & -1.718 & 2.898 & 1.047 & 0.182 \\
$T_{\min \text { back }} E$ & & 0.778 & -1.263 & 3.131 & 1.061 & 0.197 \\
$T_{\min \text { back }} K$ & $>0.887$ & 0.726 & -2.414 & 4.656 & 1.723 & 0.300 \\
$T_{\text {av back }} E$ & & -0.3810 & -2.488 & 1.063 & 0.862 & 0.160 \\
$T_{\text {av back }} K$ & $>0.593$ & -0.246 & -2.206 & 2.506 & 1.064 & 0.188 \\
$T E$ & & 0.243 & -0.171 & 0.715 & 0.219 & 0.0 .41 \\
$T K$ & $>0.133$ & 0.148 & -0.332 & 0.781 & 0.256 & 0.045
\end{tabular}

According to the conducted research and comparative analysis between the Exposure group and the Control one, we can state the following statistically $(p<0.05)$ significant decrease:

- $T_{\max }$ front increase - for $E$ group: $E=-0.58 \pm 0.2 \%$ in $66 \%$ of the examined patients, compared to $K$

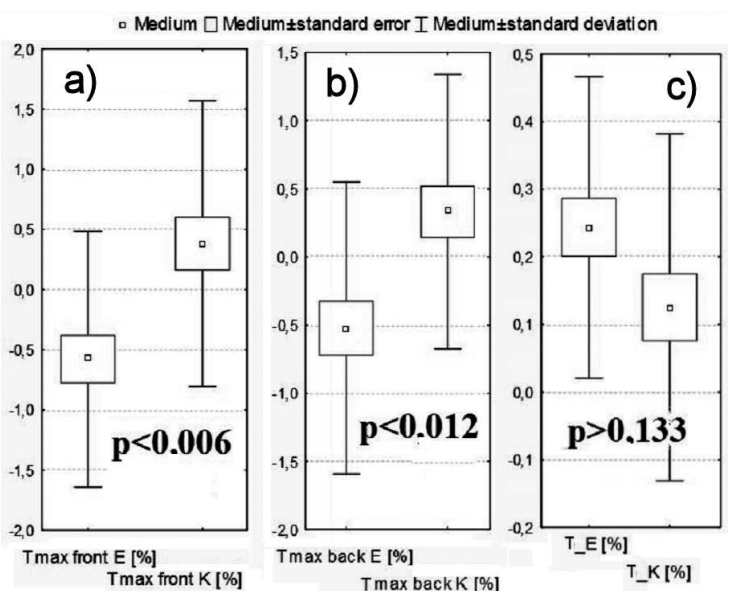

Fig. 5. Changes between $E$ and $K$ group for: (a) $T_{\max \text { front }}$, (b) $T_{\max \text { back, }}$, and (c) $T$, Results of the analysis.

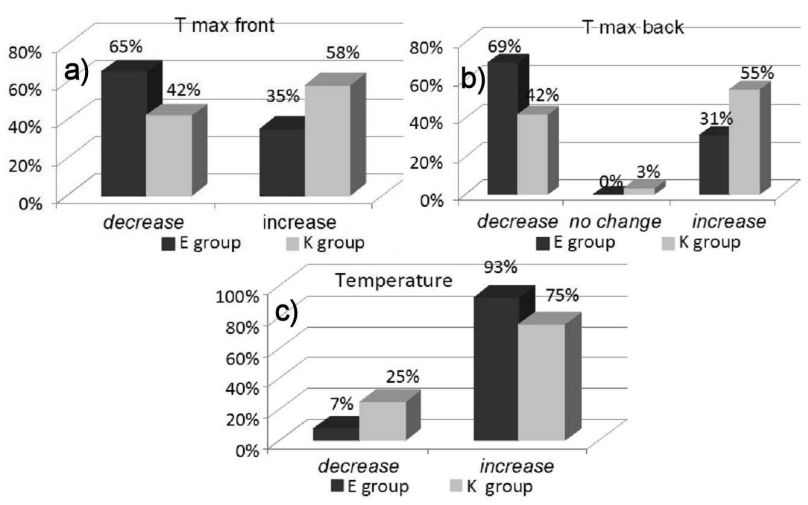

Fig. 6. Trend of changes in $E$ and $K$ group for: (a) $T_{\max }$ front , (b) $T_{\max }$ back, and (c) $T$, Results of the analysis.

group: $K=0.26 \pm 0.2 \%$ in $58 \%$ of the examined patients;

- $T_{\max }$ back increase - for $E$ group: $E=-0.52 \pm 0.2 \%$ in $69 \%$ of the examined patients, compared to $K$ group: $K=0.19 \pm 0.18 \%$ in $55 \%$ of the examined patients;

- Temperature \% increase - for $E$ group: $E=0.243 \pm$ $0.04 \%$ in $96 \%$ of the examined patients, compared to $K$ group: $K=0.148 \pm 0.045 \%$ in $75 \%$ of the examined patients.

Changes of deep temperature were not statistically significant, but almost twice as big growth of temperature was observed in the Exposure group compared to a Control one; which needs further reseArchiv.

\section{Conclusions}

During exposure to vibrations, the kinetic energy is converted into the thermal one due to active friction 
force. In 1956, Hettinger demonstrated for the first time the effect of high-frequency vibration on animal adipose tissue. General vibration is amortisable generally by muscular and skeletal systems. Contraction and decontraction of muscles, pressure of articular cartilages, micro-stresses of skeletal trabeculae, contraction and decontraction of collagen fibres in skin and fascia; all that leads to heat growth. General low-frequency vibration which is statistically significant decreases maximum temperature of legs registered in a thermographic camera at the front by $-0.58 \%$ and at the back $-0.52 \%$. In the control group, a temperature growth was observed respectively by $0.26 \%$ at the front and $0.19 \%$ at the back. During the exposure, legs play the greatest part in absorbing the stimulus as they are closest to a kinematic inductor of a vibration platform. Rhythmic work of extensor and flexor muscles of legs makes the vessels widen and greater blood supply and warming of skin and panniculus. Decrease of maximum temperature of the front and back indicates that exposure makes the redistribution of blood to the circuit - namely, from big arteries to arterlioles and muscle capillary vessels, skin and fascia tissues. Kerschan-Schnidl team made similar observation; they demonstrated faster blood circulation and decrease of vascular resistance in popliteal artery and increased number of blood vessels in a chosen muscle of calf and thigh. One may conclude that vibration stimulus largely increases blood circulation, however when overdosed, it may even lead to the damage of vessels. Applied vibration parameters seem to have a positive effect on human blood circulation as they lead to redistribution of blood circulation by widening peripheral vessels.

The experiments and analysis show that exposure to low-frequency vibration (with carefully determined parameters) is a training which improves human fitness and can be used as prevention and/or rehabilitation of many civilisation diseases such as: arterial hypertension or lack of movement (positive effect on blood circulation).

\section{References}

[1] M. Piecha, P. Król, J. Kubacki, A. Polak, A. Stanula, M. Najder, D. Chmielewska, Fizjoterapia polska 3, 6 (2006) (in Polish).

[2] M. Runge, G. Rehfeld, E. Resnicek, J. Musculoskeletal Neuronal Interact. 1, 61 (2000).

[3] J. Rittweger, G. Seller, D. Felsenberg, Clinical Physiology 20, 134 (2000).

[4] J. Rittweger, H. Schiessl, D. Felsenberg, European J. Appl. Physiology 86, 877 (2001).

[5] M. Żychowska, M. Gawinek, J. Human Kinetics 8, 77 (2002).

[6] G. Madhavan, J.M. Stewart, K.J. McLeod, Biomedical Instrumentation Technology 40, 78 (2006).

[7] K. Kerschan-Schindl, S. Grampp, C. Henk, H. Resch, E. Preisinger, V. Fialka-Moser, H. Imhof, Clinical Physiology 21, 377 (2001).

[8] M. Zazulak, Thermography. Bio-medical engineering, Ed. R. Tadeusiewicz, Wyd. AGH, Kraków 2008.

[9] Z. Damijan, A. Uhryński, Acta Physica Polonica A 118, 35 (2010).

[10] Z. Damijan, A. Uhryński, Acta Phys. Pol. A 121, A-28 (2012).

[11] D. Lepiarczyk, Polish J. Env. Stud. 21A, 276 (2012).

[12] T. Jakubowska, C. Peszyński-Drews, B. Więcek, Acta Bio-Optica Informatica Medica 12, 81 (2006) (in Polish). 